Article

\title{
Analytical Investigation and Control System Set-up of Medium Scale PV Plants for Power Flow Management
}

\author{
Antonino Oscar Di Tommaso, Fabio Genduso * and Rosario Miceli \\ Department of Electrical, Electronics and Telecommunication Engineering, Chemistry, Automation and \\ Mathematical Modeling, University of Palermo, Viale delle Scienze 90128, Palermo, Italy; \\ E-Mails: antoninooscar.ditommaso@unipa.it (A.O.D.T.); rosario.miceli@unipa.it (R.M.) \\ * Author to whom correspondence should be addressed; E-Mail: genduso@ dieet.unipa.it; \\ Tel.: +39-09123860294; Fax: +39-091488452.
}

Received: 17 September 2012; in revised form: 26 October 2012 / Accepted: 29 October 2012 /

Published: 8 November 2012

\begin{abstract}
In the field of photovoltaic (PV) plants and energy conversion from renewable sources, a large part of the technical literature is more devoted to practical aspects (new solar cells, electrically driven PV panels, safety, reduction of parasitic currents, etc.) than to theoretical investigations. Despite this tendency, this paper presents a mathematical analysis of a medium scale photovoltaic power generation system connected to the distribution network and of its control system. In such a system, the conversion stage is unique due to the absence of a boost chopper. The conducted analysis leads to the interesting conclusion that the inverter used in the plant presents two degrees of freedom, easy to exploit in a control system in which the inverter simultaneously realizes the interconnection to the grid and the MPPT control. The structure of the control system is then presented, discussed and validated by means of numerical simulations.
\end{abstract}

Keywords: photovoltaic systems; MPPT control; power electronics; PWM inverters

\section{Introduction}

Since photovoltaic (PV) installed power increases all over the world, solar technology is now strongly present in the electricity market, and it cannot be seen only as a vision of the future. As solar energy is one of the most abundant free sources in nature, the generation of electrical energy, compared with other counterparts, is effectively convenient, in particular in countries of the Mediterranean area, for 
the greater part of the year [1,2]. PV generation systems are actually available in different power sizes covering the range from domestic applications to large power generation plants.

Many different improvements have been proposed and experimented to enhance efficiency not only in energy conversion (PV fields) but also in energy management (power converters). In recent times, multi-level inverters such as H bridge multi-cell cascaded inverter [3], Neutral Point Clamped (NPC) [4] and Active Point Clamped (APC) [5] have also been used for a more efficient and effective PV power conversion [6].

Many inverter topologies have been patented, within the market development, to solve some common problems of the PV plants such as leakage currents due to parasitic capacitance of the panel and efficiency losses due to the transfer of reactive energy between the grid filters and the DC bus capacitor [7-9]. Moreover, some particular topologies have been conceived of for the fault tolerant operation of PV plant [10-16]. Many of the novel patented circuits can operate without boost choppers and high frequency transformers, while on the other hand ancillary functions require more flexibility in the control design [6,17]. As foreseen in recent investigations, all the emerging technologies have been recently employed to optimize the electricity production from solar energy. In particular, MPPT control (Maximum Power Point Tracking) is one of the most interesting aspects of renewables. In general, a boost chopper is used to follow the maximum power point, while inverters are used only to adjust voltages and currents to meet the load/grid requirements [18-21]. Therefore, a boost chopper is very often integrated in the most utilized all-in-one commercial PV power converters. The use of boost choppers, however, contributes to reduce the reliability, the efficiency and the economical convenience, due to the presence of cascaded converters and the higher complexity of the control system [22].

In more recent times, the possibility of realizing the MPPT control in grid-connected systems without AC voltage boosts, directly with transformers or passive filters, has been studied and discussed [23]. This paper presents an analytical and numerical investigation on a medium scale PV power generator connected to an active network with its power flow and MPPT control system. The analysis here shows that the inverter presents two degrees of freedom. In particular, these two degrees of freedom consist in two control variables, the direct and the quadrature line axis current components, which can be profitably utilized to control the active power, the reactive power and the MPPT at the same time.

\section{The Plant under Analysis and Its Modeling}

The plant under investigation consists of a PV generator directly coupled with a Voltage Source Inverter (VSI) as said in the introduction. A simplified scheme of the system is shown in Figure 1. The inverter is connected to the network or to the load through an intermediate LC filter to meet power quality grid requirements. If an output transformer is required, the filter can be made of the short circuit transformer impedance and by a capacity bank.

The authors here recall the model equations of each component used to build the model of the whole system.

For the PV Generator, in the most cases, the Hussain model is considered [24] [see Equation (1)].

$$
i=i_{P V}-I_{0 r e v}\left(\exp \left(\frac{q\left(v_{P V}+i R_{s}\right)}{n K T}\right)-1\right)
$$


Figure 1. Scheme of the plant under investigation.
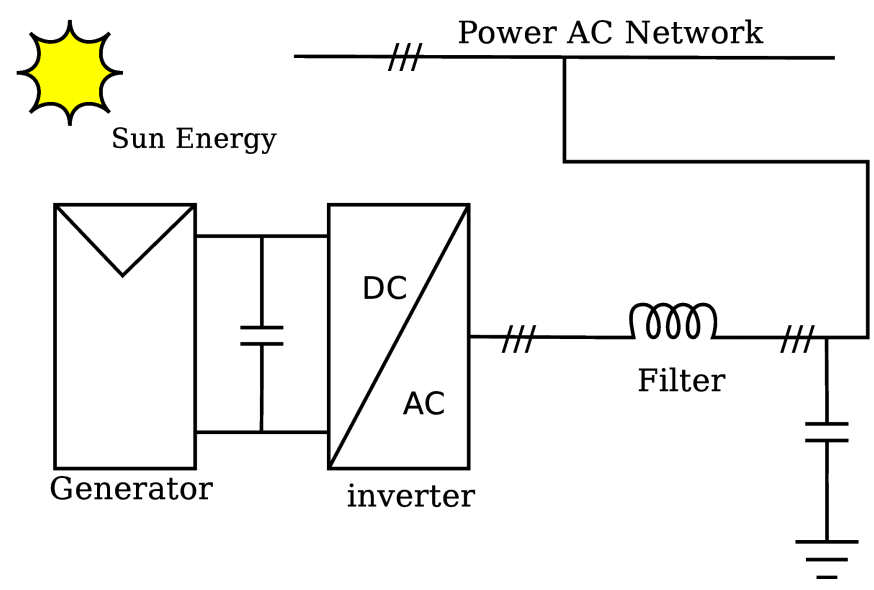

where:

- $i$ is the output current;

- $i_{P V}$ is the sun generated current;

- $I_{0 r e v}$ is the PN junction reverse current;

- $q$ is the electron charge;

- $v_{P V}$ is the output voltage;

- $R_{S}$ is the internal cell resistance;

- $n$ is a quality factor depending on the cell type;

- $K$ is the Boltzmann constant;

- $T$ is the absolute temperature.

For the three-phase inverter and the grid, the model is written directly in $D Q 0$ reference frame to achieve a completely DC model. The fixed three-phase to rotating reference frame transformation is represented by the matrix:

$$
\sqrt{\frac{2}{3}}\left(\begin{array}{ccc}
\cos (\theta) & \cos \left(\theta-\frac{2 \pi}{3}\right) & \cos \left(\theta+\frac{2 \pi}{3}\right) \\
-\sin (\theta) & -\sin \left(\theta-\frac{2 \pi}{3}\right) & -\sin \left(\theta+\frac{2 \pi}{3}\right) \\
\frac{1}{\sqrt{3}} & \frac{1}{\sqrt{3}} & \frac{1}{\sqrt{3}}
\end{array}\right)
$$

with $\theta=\omega t=2 \pi f t$ where $f$ is the grid frequency and $t$ is the time. In the $D Q 0$ rotating reference frame the inverter equations are given by:

$$
\begin{aligned}
C \frac{d u_{D C}}{d t} & =i_{0}-\left(S_{D} i_{D}+S_{Q} i_{Q}\right) \\
v_{D} & =S_{D} u_{D C} \\
v_{Q} & =S_{Q} u_{D C}
\end{aligned}
$$


where:

- $C$ is the DC Link capacitance.

- $u_{D C}$ is the DC-link voltage;

- $i_{0}$ is the input inverter current;

- $S_{D}$ and $S_{Q}$ are the direct and quadrature components of the inverter switching functions;

- $i_{D}$ and $i_{Q}$ are the direct and quadrature components of inverter output current;

- $v_{D}$ and $v_{Q}$ are the direct and quadrature components of inverter output voltage.

The inverter input current is, instead, given by the equation:

$$
v_{P V}-u_{D C}=R_{0} i_{0}+L_{0} \frac{d i_{0}}{d t}
$$

where $R_{0}$ and $L_{0}$ are, respectively, the resistance and the inductance of the wiring between the PV generator and the inverter.

For the active power grid the model equations are:

$$
\begin{aligned}
& v_{D}=R i_{D}+L \frac{d i_{D}}{d t}-\omega L i_{Q}+e_{D} \\
& v_{Q}=R i_{Q}+L \frac{d i_{Q}}{d t}+\omega L i_{D}+e_{Q}
\end{aligned}
$$

In this case, $R$ and $L$ are the resistance and the inductance of the grid till to a prevalent power node, and $e_{D}$ and $e_{Q}$ are the direct and quadrature components of the grid voltage in the prevalent power node.

It is usual, for systems including power converters, to consider the averaged model.

Averaging the model implies to consider the "instantaneous" mean value of each quantity $x_{a v}(t)$ defined by:

$$
x_{a v}(t)=\frac{1}{T_{P W M}} \int_{t}^{t+T_{P W M}} x(\tau) d \tau
$$

in which $T_{P W M}$ is the converter switching period.

By considering now the steady state and remembering that in the average model the switching functions $S_{k}$ are to be replaced with duty cycles $F_{k}$ [20,21], the system model becomes (with $a v$ subscript omitted):

$$
\left\{\begin{array}{l}
V_{P V}-U_{D C}=R_{0} I_{0} \\
V_{D}=F_{D} U_{D C} \\
V_{Q}=F_{Q} U_{D C} \\
I_{0}=F_{D} I_{D}+F_{Q} I_{Q} \\
V_{D}=R I_{D}-\omega L I_{Q}+E_{D} \\
V_{Q}=R I_{Q}+\omega L I_{D}+E_{Q}
\end{array}\right.
$$


Capital letters are just used here to point out steady state. Equation (7) comes from Equations (3-5), rewritten by vanishing all the derivatives because after the DQ transformation the system is a DC one. The nonlinear Equation (7) clearly has no closed form solution. Solving the two last equations of the system (7) with respect to the current components, one finds:

$$
\begin{aligned}
& I_{D}=\frac{\left(V_{D}-E_{D}\right) R+\left(V_{Q}-E_{Q}\right) \omega L}{R^{2}+(\omega L)^{2}} \\
& I_{Q}=\frac{\left(V_{Q}-E_{Q}\right) R+\left(E_{D}-V_{D}\right) \omega L}{R^{2}+(\omega L)^{2}}
\end{aligned}
$$

Substituting Equation (8) into the fourth equation of the system [Equation (7)], the explicit expression of $I_{0}$ is obtained:

$$
I_{o}=\frac{\left(\left(F_{Q}^{2}+F_{D}^{2}\right) U_{D C}-E_{Q} F_{Q}-E_{D} F_{D}\right) R+\left(E_{D} F_{Q}-E_{Q} F_{D}\right) \omega L}{R^{2}+(\omega L)^{2}}
$$

If the DQ reference frame is chosen with the D axis coinciding with the vector of the grid voltage, the previous expression simplifies to:

$$
I_{0}=\frac{\left(\left(F_{Q}^{2}+F_{D}^{2}\right) U_{D C}-U_{\text {grid }} F_{D}\right) R+\omega L U_{\text {grid }} F_{Q}}{R^{2}+(\omega L)^{2}}
$$

where $E_{D}=U_{\text {grid }}$ and $E_{Q}=0$. After some algebraic manipulations, one has:

$$
F_{D}^{2}+F_{Q}^{2}-\frac{F_{D} U_{\text {grid }}}{U_{D C}}+\frac{F_{Q} U_{\text {grid }} X}{U_{D C} R}-\frac{I_{0} Z^{2}}{U_{D C} R}=0
$$

where $X=\omega L$, and $Z=\sqrt{R^{2}+X^{2}}$. It is obvious that if the PV generator gives constant power, then $U_{D C}$ and $I_{0}$ are fixed. Therefore, in Equation (11) $F_{D}$ and $F_{Q}$ assume the values for which the inverter transfers a given power generated by the PV panel. Equation (11) represents, therefore, the "constant power circles" in the $F_{D}-F_{Q}$ plane. A plot of these circles is given in Figure 2.

The coordinates of the circle centers are:

$$
C:=\left(\frac{U_{\text {grid }}}{2 U_{D C}} ;-\frac{X}{R} \frac{U_{\text {grid }}}{2 U_{D C}}\right)
$$

and the circle radii are:

$$
r=\sqrt{\frac{U_{g r i d}^{2}}{4 U_{D C}^{2}}\left(1+\frac{X}{R}\right)+\frac{Z^{2} I_{0}}{U_{D C} R}}
$$

The centers lie on a line whose slope is $-X / R$. The singular locus corresponding to the short circuit condition (zero-power) of the PV generator is represented by Equation (14).

$$
-F_{D}+\frac{X}{R} F_{Q}=\frac{Z^{2} I_{0}}{R U_{\text {grid }}}
$$


Figure 2. Constant Power Circles on the $F_{D}--F_{Q}$ plane.

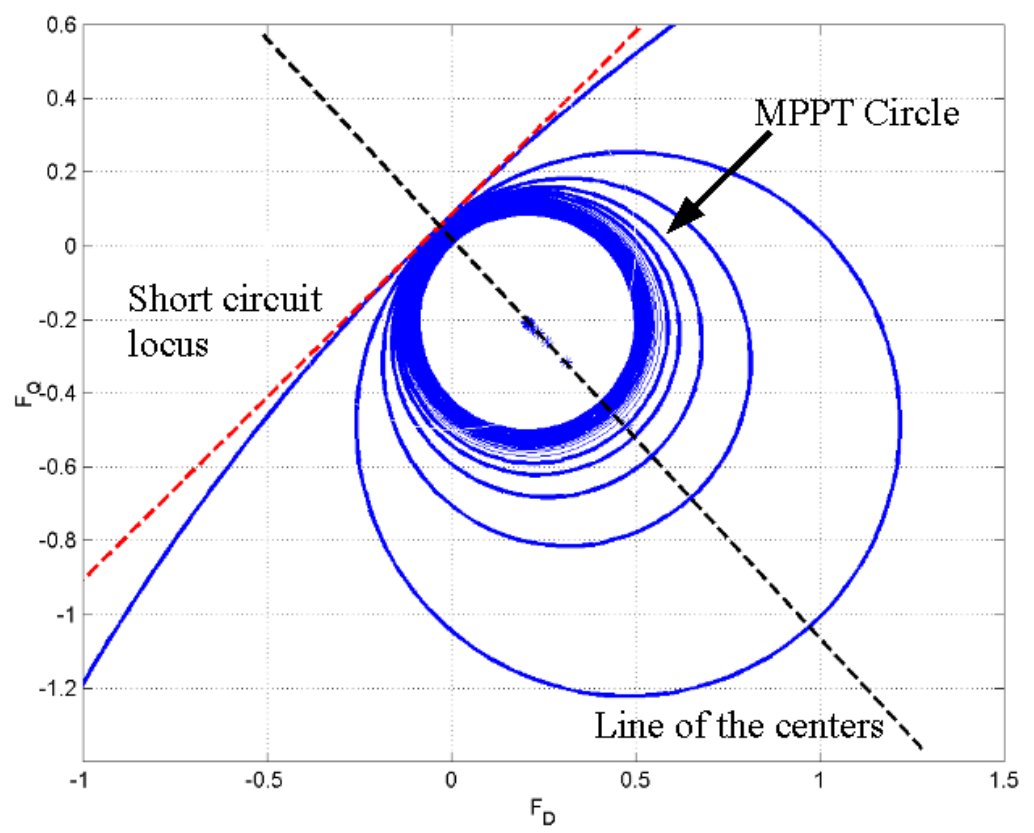

The constant power circles are very close to each other in the quasi-constant voltage region of the PV voltage-current characteristic, while they are more sparse in the quasi-constant current region. Between these two regions, the Maximum Power circle is located. The transmission of a particular value of active power to the AC network may be realized with different $F_{D^{-}} F_{Q}$ values (theoretically all the $F_{D^{-}} F_{Q}$ pairs of a constant power circle). This corresponds to different values of inverter voltage and current, i.e., different values of the reactive power, with active power constrained by the PV generator. In general, the inverter may be controlled with two degrees of freedom, which are the $I_{D}$ and the $I_{Q}$ components. These components can be fully exploited only if the D-Q channels are decoupled.

In order to determine the $I_{D}$ and $I_{Q}$ expressions, the active power balancing Equation (15) and the expression of the reactive power [Equation (16)] are considered.

$$
U_{D C} I_{0}=R\left(I_{D}^{2}+I_{Q}^{2}\right)+U_{\text {grid }} I_{D}
$$

where $U_{D C} I_{0}$ is the generated power, $R\left(I_{D}^{2}+I_{Q}^{2}\right)$ represents the chopper losses, and $U_{\text {grid }} I_{D}$ is the active power delivered to the grid.

$$
Q=U_{\text {grid }} I_{Q}
$$

The solution of Equations (15) and (16) leads to the following values of the current components:

$$
\begin{gathered}
I_{D}=\frac{\sqrt{4 I_{o} U_{D C} U_{g r i d}^{2} R-4 Q^{2} R^{2}+U_{g r i d}^{4}}-U_{\text {grid }}^{2}}{2 R U_{\text {grid }}} \\
I_{Q}=\frac{Q}{U_{\text {grid }}}
\end{gathered}
$$


The knowledge of $I_{D}$ and $I_{Q}$ allows the full determination of the output inverter voltage vector. The intersection of this vector with the proper constant power circle allows, finally, the determination of $F_{D}$ and $F_{Q}$ for the inverter control.

The presented mathematical model cannot be immediately and effectively exploited for the control of the three-phase inverter without carrying out an accurate system identification parameters. Nevertheless, to overcome this drawback, the results of the conducted analysis suggest the structure of the closed loop control system, which will be discussed in the next section.

\section{The System for Power Flow Control}

The chosen control system has the structure plotted in the block scheme of Figure 3.

Figure 3. Block scheme of the control system.

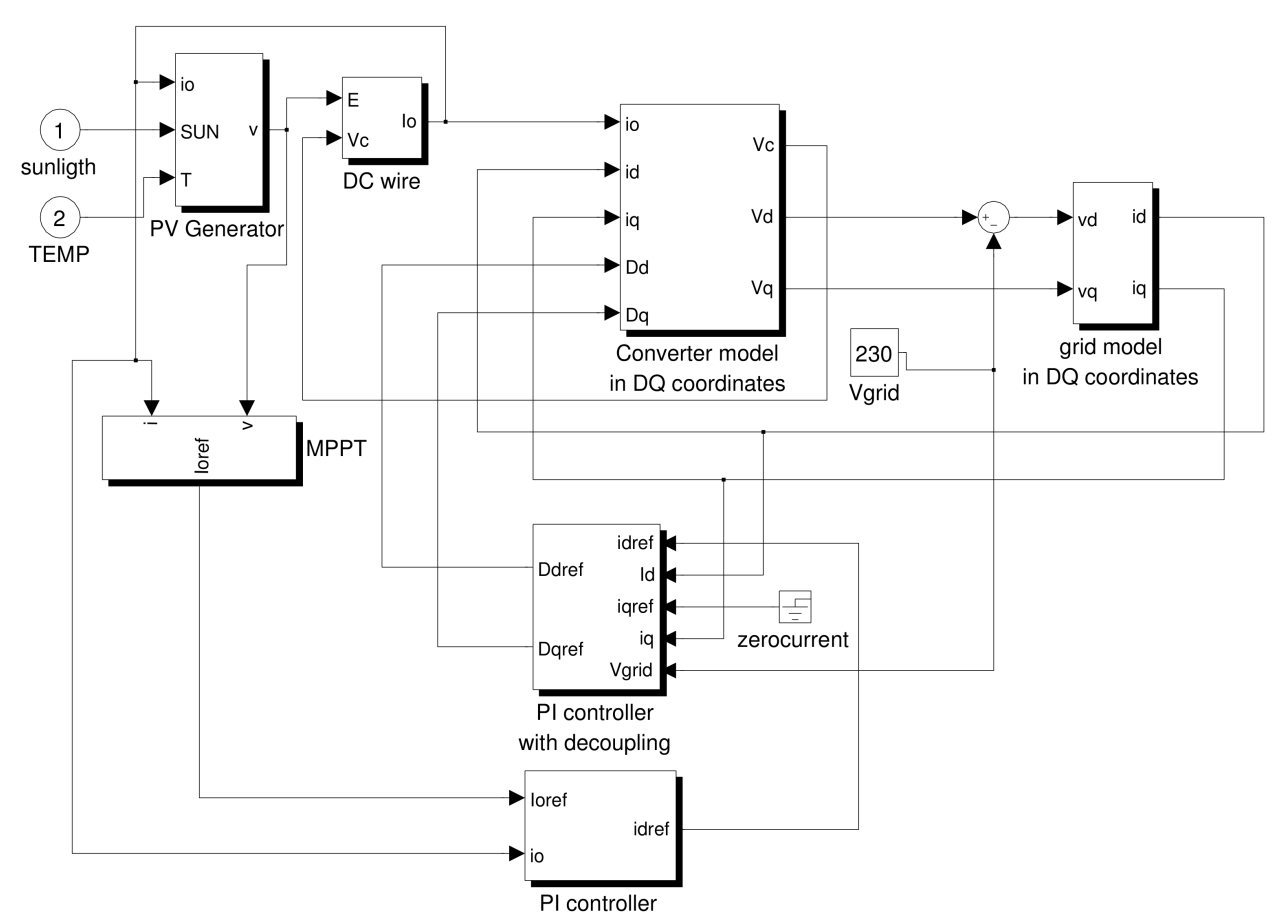

The system has two nested control loops. The innermost loop uses two decoupled current regulators for the $\mathrm{D}$ and the $\mathrm{Q}$ channels. The outermost loop uses, instead, a single regulator generating the $I_{D}$ current reference coming from the MPPT system output.

The DQ inverter equations suggest that for MPPT purposes the current $I_{o}$ can be regulated by varying the DC link voltage with respect to that of the PV generator. The same equations suggest that the DC link voltage can be varied by controlling a current, namely $I_{D}$ or $I_{Q}$. By synchronizing the reference frame so that its $\mathrm{D}$ axis overlaps the grid voltage vector, the $I_{D}$ regulation channel is used for the adjustment of $U_{D C}$ and $i_{0}$, i.e., for active power regulation, while the $I_{Q}$ regulation channel is used to vary reactive power. When the $I_{Q}$ reference is set to zero, the control system provides the injection in the network of active power only. A non-zero $I_{Q}$ value may be chosen on the basis of reactive power grid demand. However, reactive power values cannot be very high because its transmission can cause large fluctuations in the DC Link voltage around its mean value and makes stability a critical issue for the system. 
Stability analysis considers the transfer function for small signals binding the $i_{0}$ current reference to its actual value. A linearized version of the system may be reached by considering the inner control loop behavior as instantaneous and the voltage-current link of the PV panel as linear near the maximum power point $\left(V_{P V}=-K_{P V} I_{0}\right.$, where $K_{P V}$ is the slope of the $\mathrm{V}-\mathrm{I}$ generator characteristic at a steady state working point). A block scheme of the outer control loop is resumed in Figure 4.

Figure 4. Scheme of the linearized outer control loop of the plant.

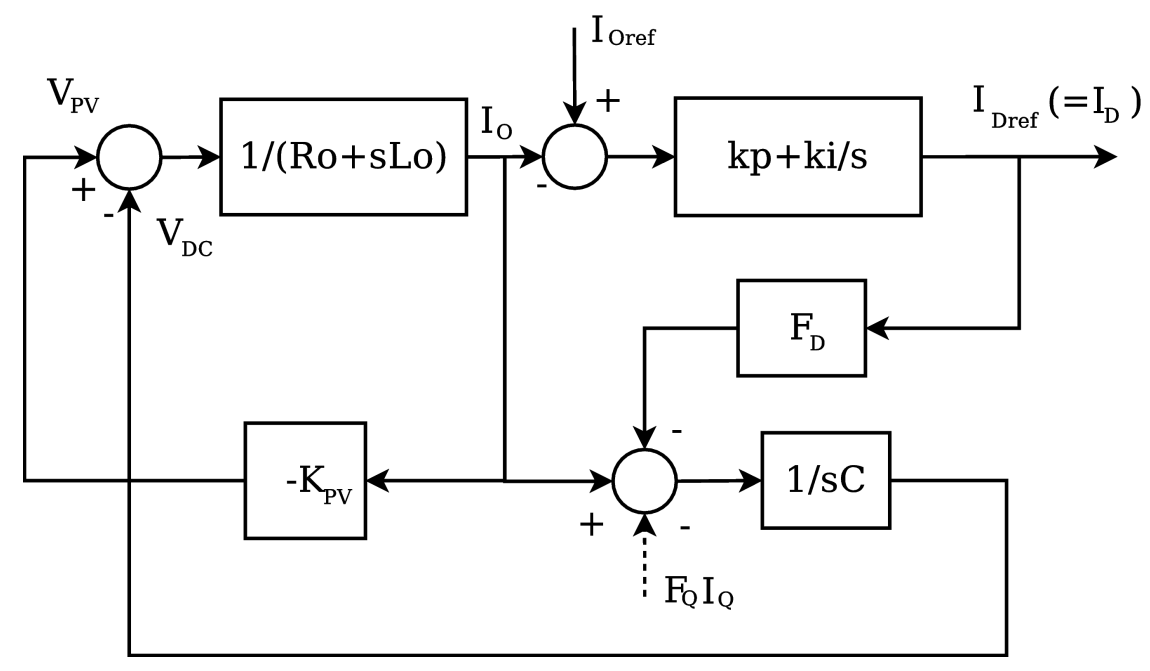

For the sake of simplicity, no action of the quadrature channel is considered because it does not change the system poles. After the linearization, by analyzing the scheme of Figure 4, the following transfer function results:

$$
\frac{I_{o}}{I_{\text {oref }}}=\frac{F_{D}\left(k_{p} s+k_{i}\right)}{L_{o} C s^{3}+C\left(R_{o}+K_{P V}\right) s^{2}+\left(F_{D} k_{p}+1\right) s+F_{D} k_{i}}
$$

where $k_{p}$ and $k_{i}$ are the regulator parameters.

By applying the Routh Criterion, the stability condition is found at:

$$
\left(R_{o}+K_{P V}\right)\left(F_{D} k_{p}+1\right)-L_{o} C k_{i}>0
$$

Robust stability is guaranteed if the polynomial in Equation (20) is positive and far away from zero considering all the $K_{P V}$ values in a wide range near the maximum power point for the generator. Obviously, the stability condition, formed for the linearized system, provides only a first choice to be refined and must be verified experimentally on the real system for possible adjustments.

The MPPT algorithm provides, therefore, the value of $I_{o}$ corresponding to the maximum power transfer. The error signal is processed by the PI controller that provides the $I_{D}$ current set-point. The reference signal for $I_{Q}$ is null or independently generated depending on the grid demands.

The control system requires the presence of a PLL (Phase Locked Loop) device both for synchronization and for giving effect to the decoupling of the D and Q control channels. This is usually a common issue for grid connected power PV systems.

Although the problem of the inverter-network synchronization is outside the aims of this article, it is interesting to recall that, recently, the solutions to this problem have gained considerable 
advances [6,25]. The SOGI (Second Order Generalized Integrator) has been used as a Quadrature Signal Generator (QSG-SOGI) in PLLs achieving smaller steady state disturbances [26,27]. On further investigations, the SOGI-FLL (Frequency Locked Loop SOGI) was realized. Its later upgrade with gain normalization has increased the stability margins of the frequency and phase follower. In both systems it is simple to set the specific time response even at adverse grid conditions (e.g., harmonic distortion, flickering, voltage sags, etc.) [28].

Figures 5 and 6 show the block diagrams of QSG-PLL and SOGI-FLL.

Figure 5. Quadrature signal based PLL with a SOGI-QSG system ( $q v$ is a quadrature signal with respect to $v$ ).

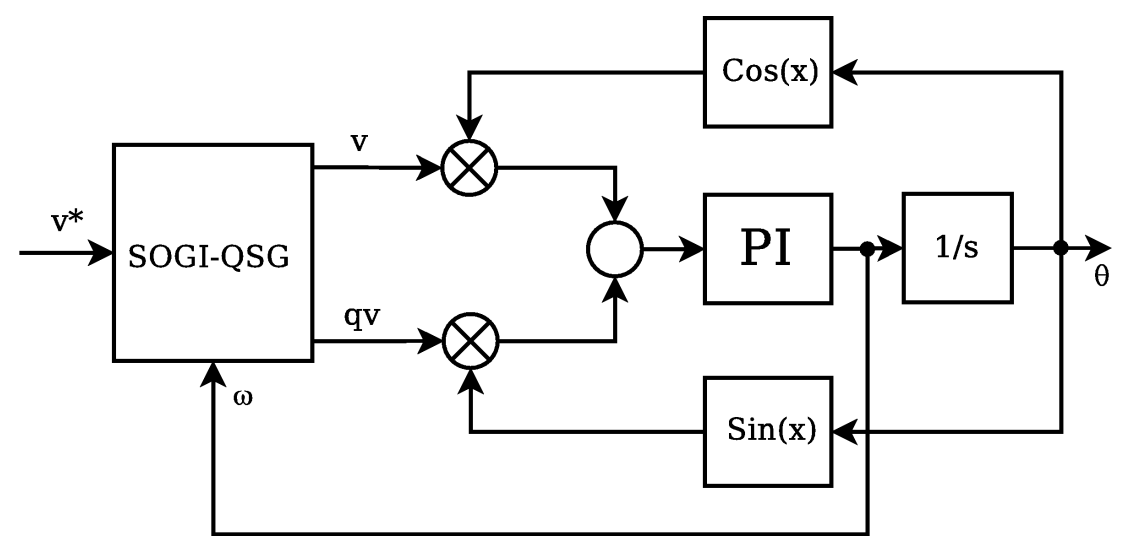

Figure 6. Scheme of the SOGI-FLL system (The gain normalization block provides $\left.1 / \sqrt{v^{2}+q v^{2}}\right)$.

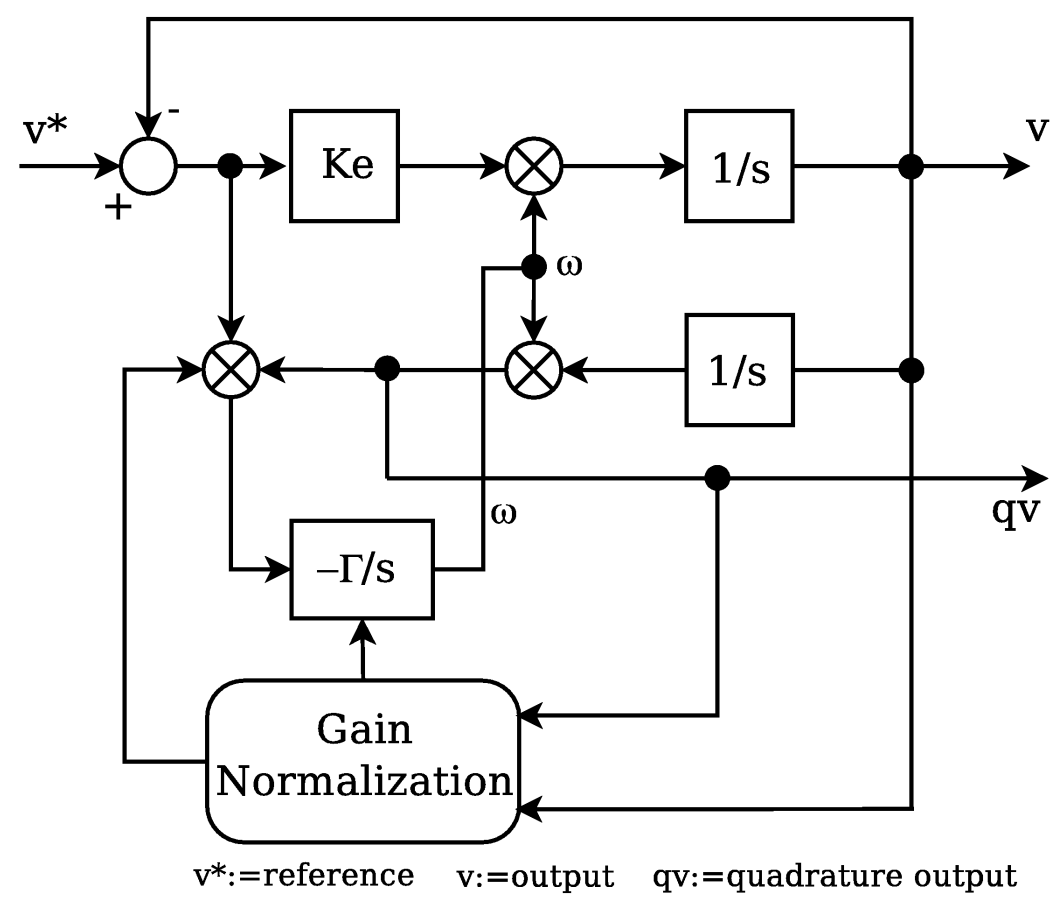




\section{Simulations}

Many different simulations were made to verify the validity of the control system. These simulations have been carried out with MATLAB Simulink software package, building the control scheme of Figure 3 directly in the DQ coordinate reference frame, and using the inverter average model. By using the average model, the ripple of all variables is neglected, so simulation results appear to be smooth. Grid side voltages and currents are back transformed in the fixed three-phase reference frame to be plotted as sinusoidal signals.

Simulation results are shown in the per-unit systems. In particular, for PV DC-side quantities, the reference values are the no load voltage and the short circuit currents at standard conditions, i.e., $T=25^{\circ} \mathrm{C}$ and $S=1 \mathrm{~W} / \mathrm{m}^{2}$ irradiation, air mass 1.5 , no wind [2]. For the AC-side quantities, the reference voltage is the peak value of the rated grid voltage and the reference current is that corresponding to the maximum active power peak at the standard condition specified above.

Various events have been considered in the simulations for the transient study. Among them, the following are considered to evaluate the control performance:

1. a low change in the weather conditions (e.g., sunspot, temperature, effect of a fast passing cloud) at $\cos \phi=1$ in the time range $3-6 \mathrm{~s}$;

2. a step change in reactive power demand with all other stationary conditions at $t=7 \mathrm{~s}$;

3. a grid voltage peak step change (under-voltage, 15\%) at $t=10 \mathrm{~s}$.

Figure 7 shows voltages and currents on the grid side at steady state with zero reactive power delivered before the weather perturbation occurs. In this condition, the control system manages the output voltages to hold the output currents in phase with the grid voltage. Null power factor is maintained also if a change in weather condition occurs. Figure 8 shows, instead, the same voltages and currents at steady state with a non-zero reactive power demand.

Figure 9 shows the variation of the DC Link voltage as a consequence of the control system operation to reach the peak power after a slow weather change developed in about $3 \mathrm{~s}$. With evidence of Figure 9, a very small voltage variation is required to adjust the current $I_{0}$ because of the small impedance of DC wires connecting the PV generator and the inverter.

Figure 9 shows also the effect on DC Link voltage of the step change in reactive power demand at $t=7 \mathrm{~s}$. The reactive power step has a poor influence on the DC Link voltage. However, after the small transient, the steady state value of $u_{D C}$ does not change.

Figure 10 shows the transient of the output currents (with the grid voltages plotted in red) on the AC-side due to a change of the $I_{0}$ reference given by the MPPT algorithm. The variation of currents is slow like the change in the weather condition detected by the power peak tracker. 
Figure 7. Grid Voltages and Currents (in p.u. system) at steady state for zero reactive power delivered.

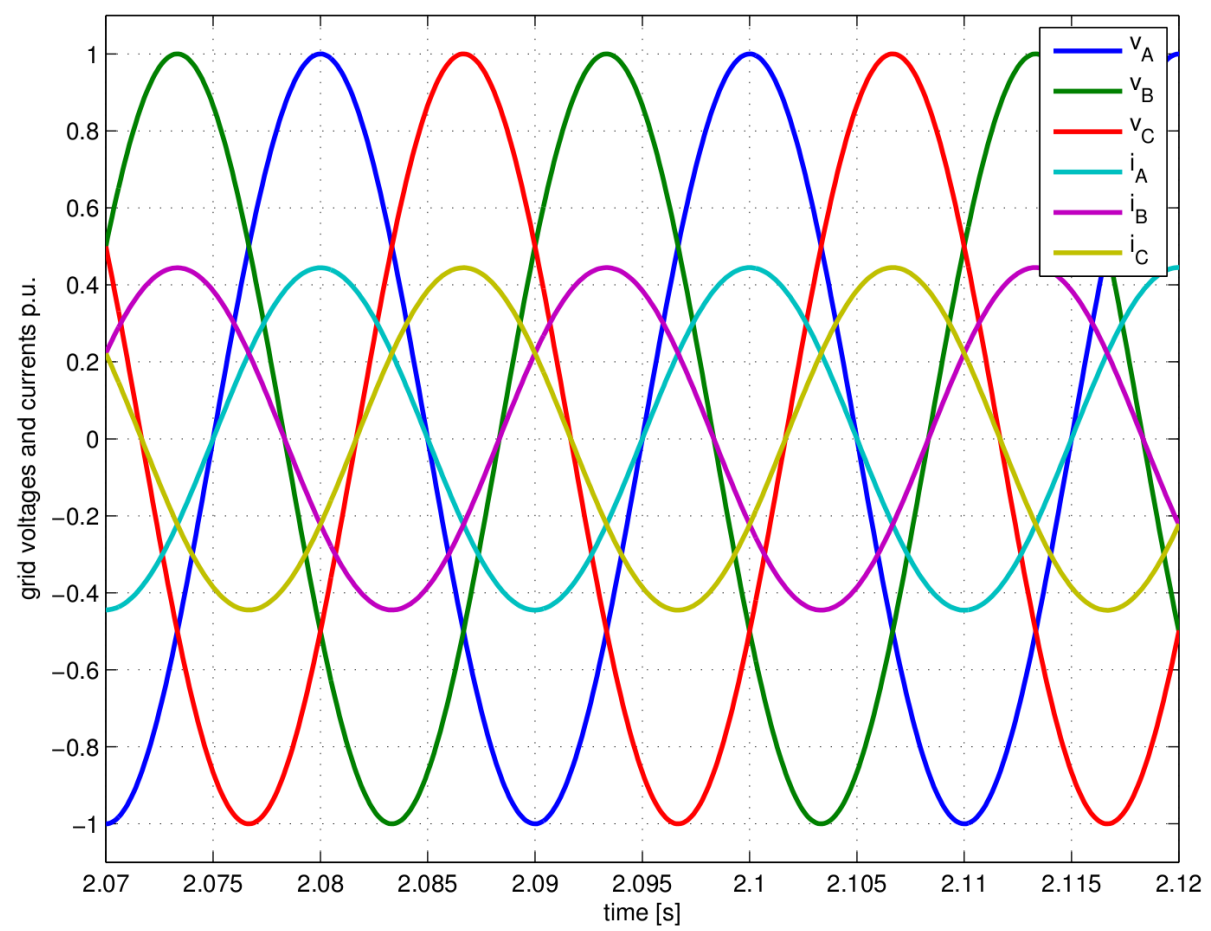

Figure 8. Grid side voltage and currents (in p.u. system) at steady state for non-zero reactive power (color legend is the same as in Figure 7).

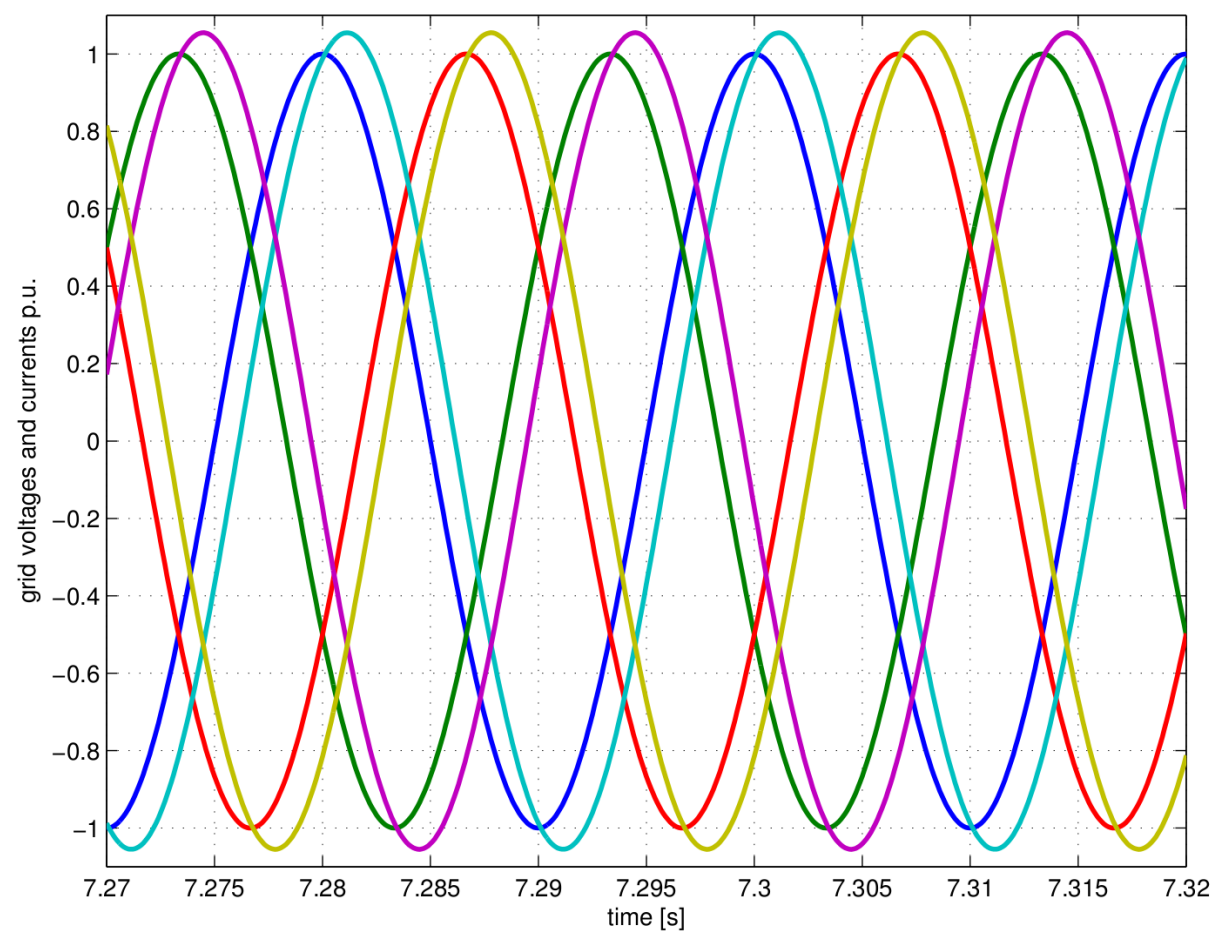


Figure 9. Variation of the DC Link voltage during the intervention of the control system.

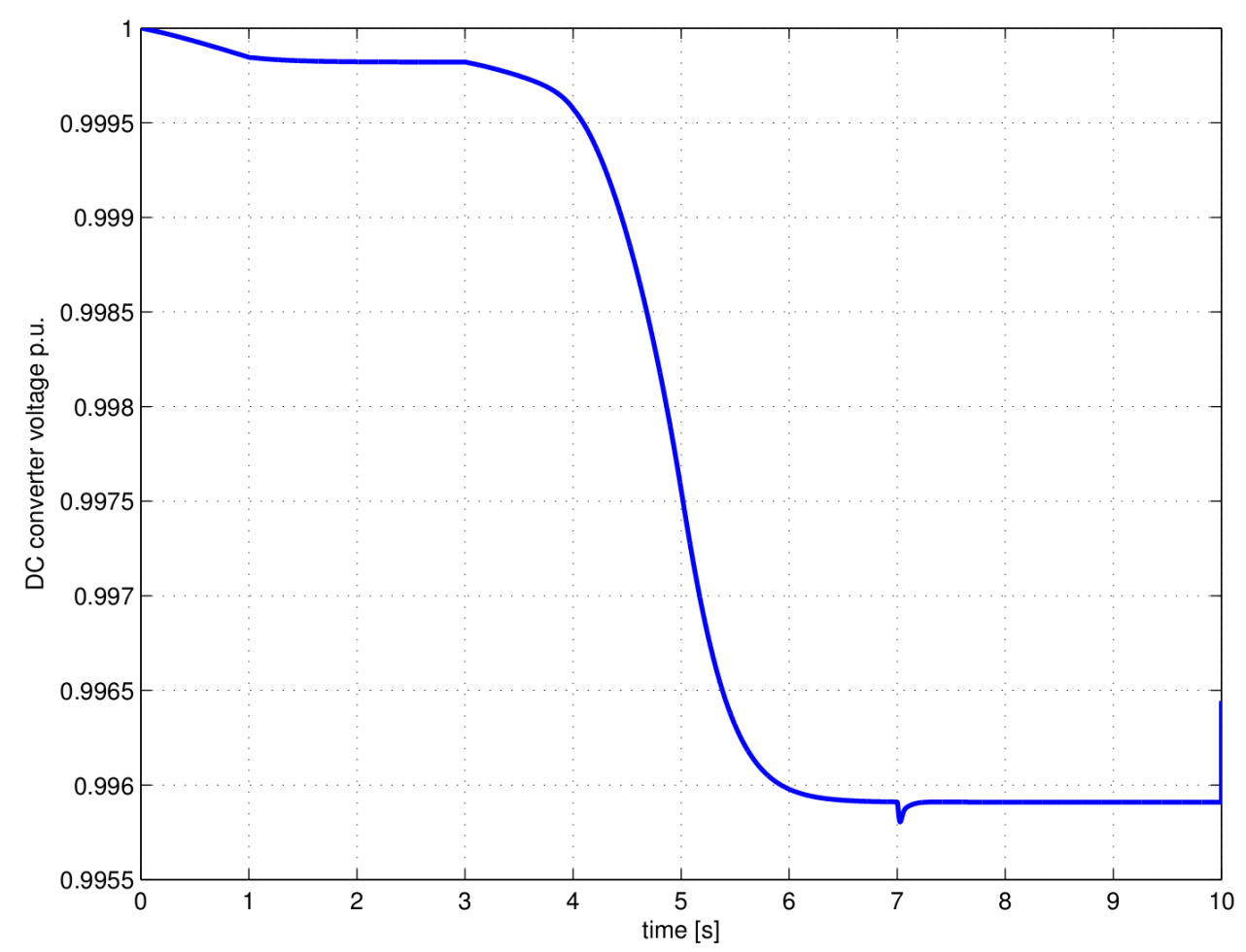

Figure 10. Grid Voltages (red) and Currents (yellow) variation in p.u. due to a slow change of reference of the power peak tracker.

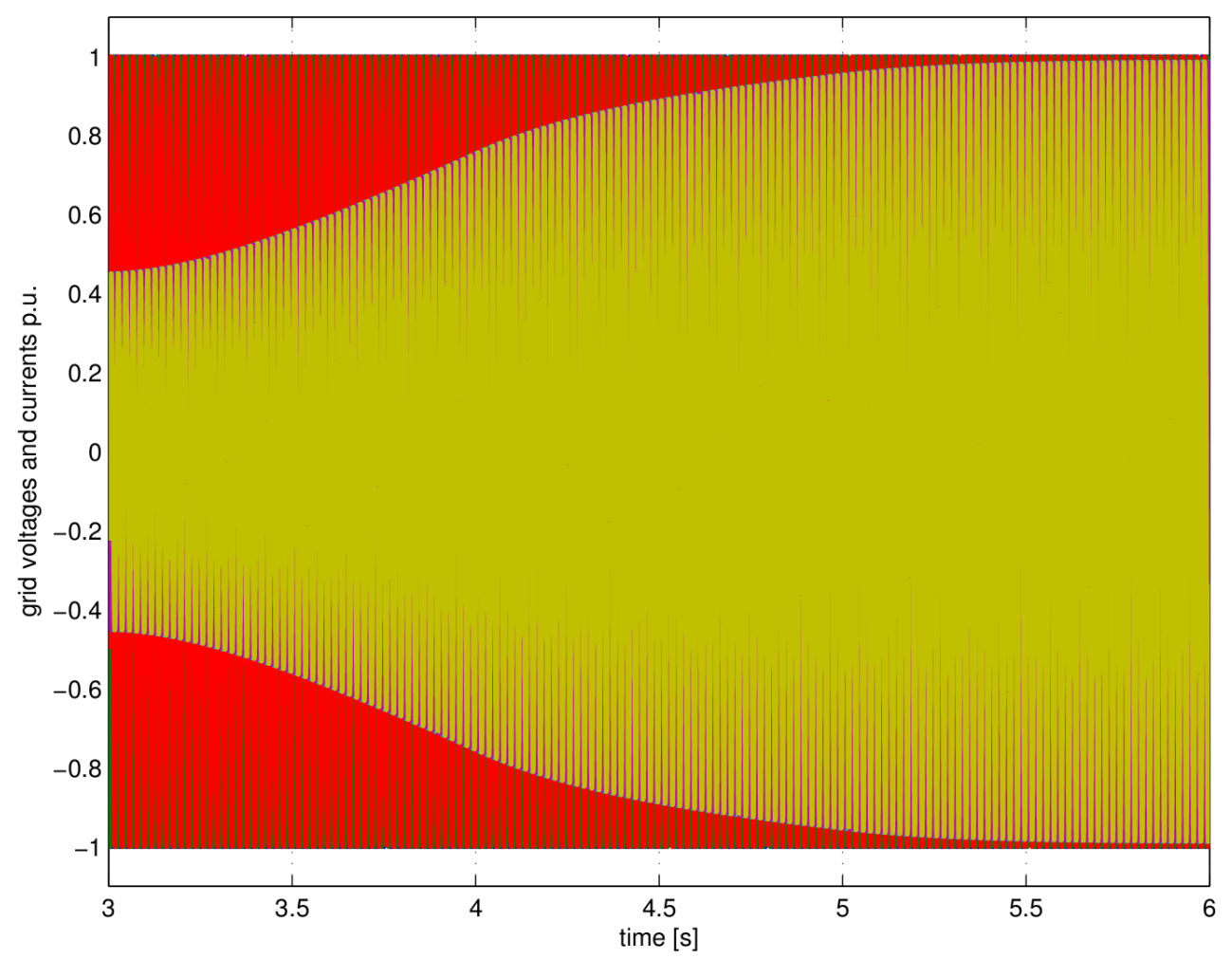


The same variation is shown in Figure 11 (considering the time range 3-6 s) for the direct and the quadrature current components.

The power peak tracker modifies the $I_{o}$ reference. These values reflect on the $i_{D}$ reference, so the currents on the DC and AC sides are adjusted acting on the inverter duty cycles. It is quite evident that weather condition cannot change instantaneously, so even if the control loop is slow, the whole system performance will not be reduced. This claim is more evident by considering that at time $t=7 \mathrm{~s}$, the $i_{Q}$ reference has a step change due to reactive power demand. In this case, the system reaction is very fast because only the inner control loop operates. Furthermore, the regulation channel for $i_{D}$ is reasonably insensitive during the transient, due to the feedforward decoupling. A complete insensitivity between channels is not strictly possible because of numerical approximation, but in practical cases, the decoupling degree is sufficient to guarantee a good performance. Finally, the simulation of a grid under-voltage event ( $15 \%$ on voltage peak, $t=10 \mathrm{~s}$ ), is considered.

Figure 11. Direct and quadrature components of the AC side currents during transients (change of $i_{D}$ reference from MPPT and change of Q).

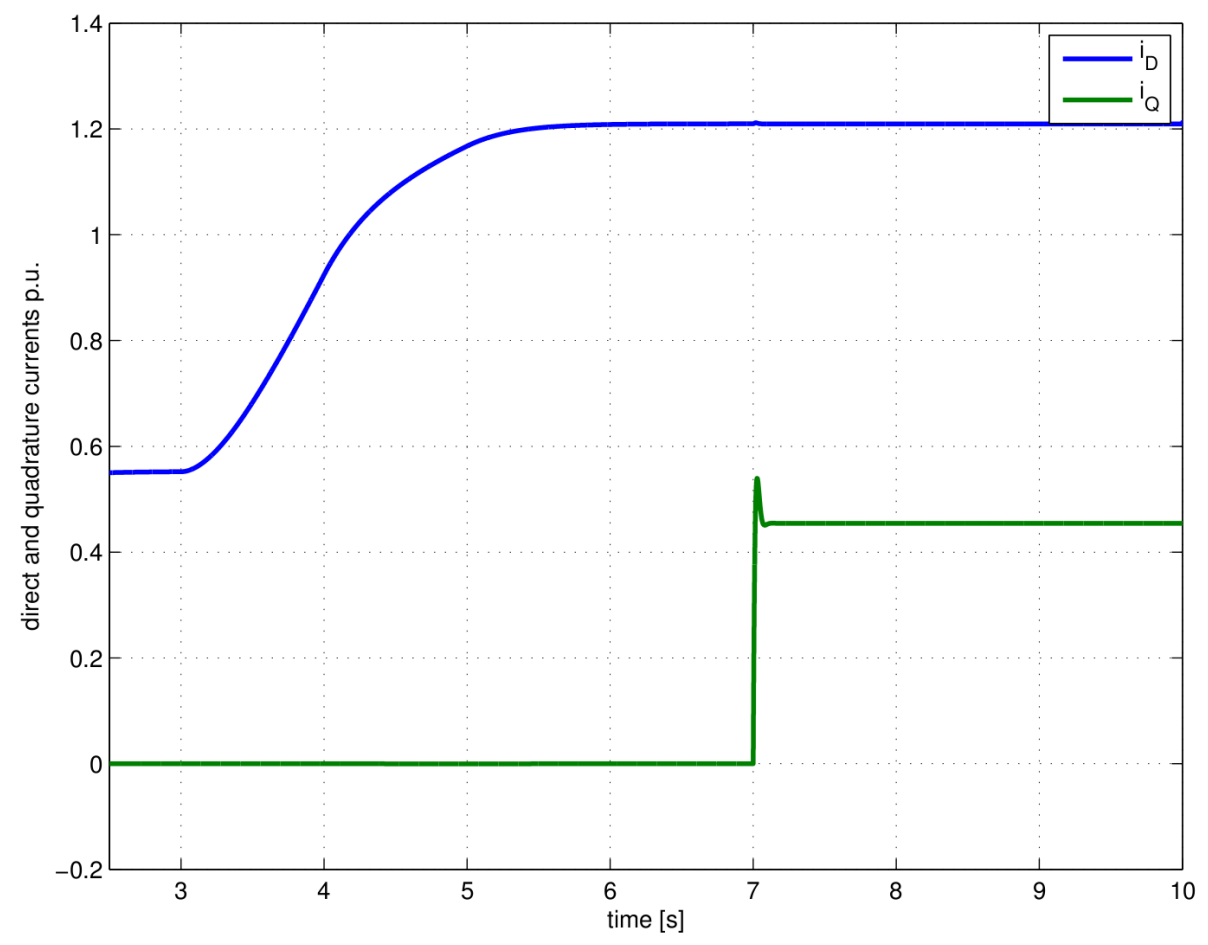

Figure 12 shows, in particular, the grid voltage plot before and after the event and the corresponding plot of the grid currents, as the control system operates to maintain constant values for active and reactive power.

The transient evolution is more plain with a glance at the plots of $i_{D}, i_{Q}$ (Figure 13) and $u_{D C}$ (Figure 14). Figure 13 shows the transient variation of $i_{D}$ and $i_{Q}$. In the present case, only the direct current component changes. The quadrature component remains instead constant being no additional request for reactive power.

During the transient, there is an initial drop of the active power delivered by the converter. This is followed by a quick recovery action of the control system. As to be expected, at the beginning, the DC 
link voltage has a small increase (0.003 p.u.). After the control recovery, the voltage comes back to the initial value and is then kept constant, as shown in Figure 14.

Figure 12. Grid under-voltage and the corresponding current transient.
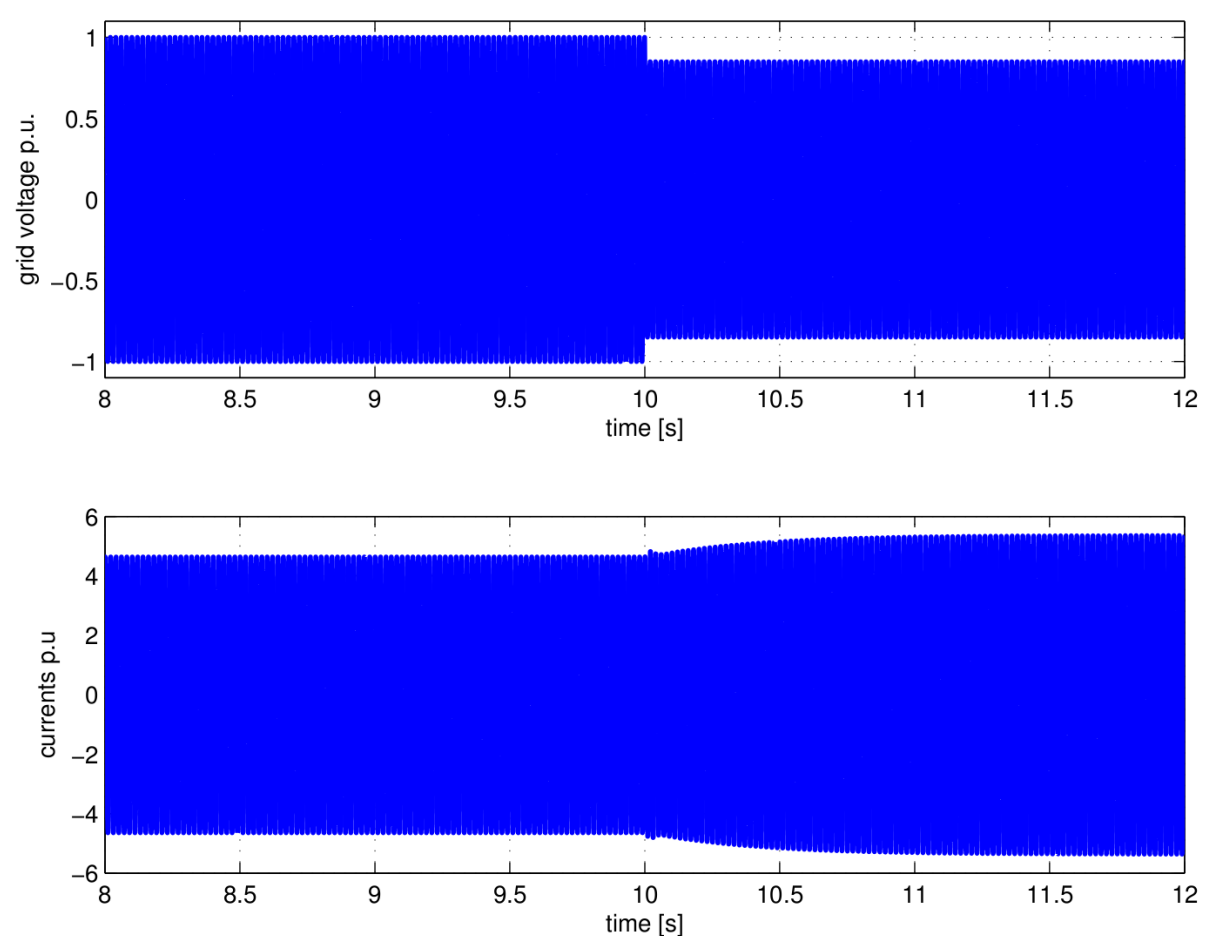

Figure 13. Simulated transients of $i_{D}$ and $i_{Q}$ after the grid under-voltage.

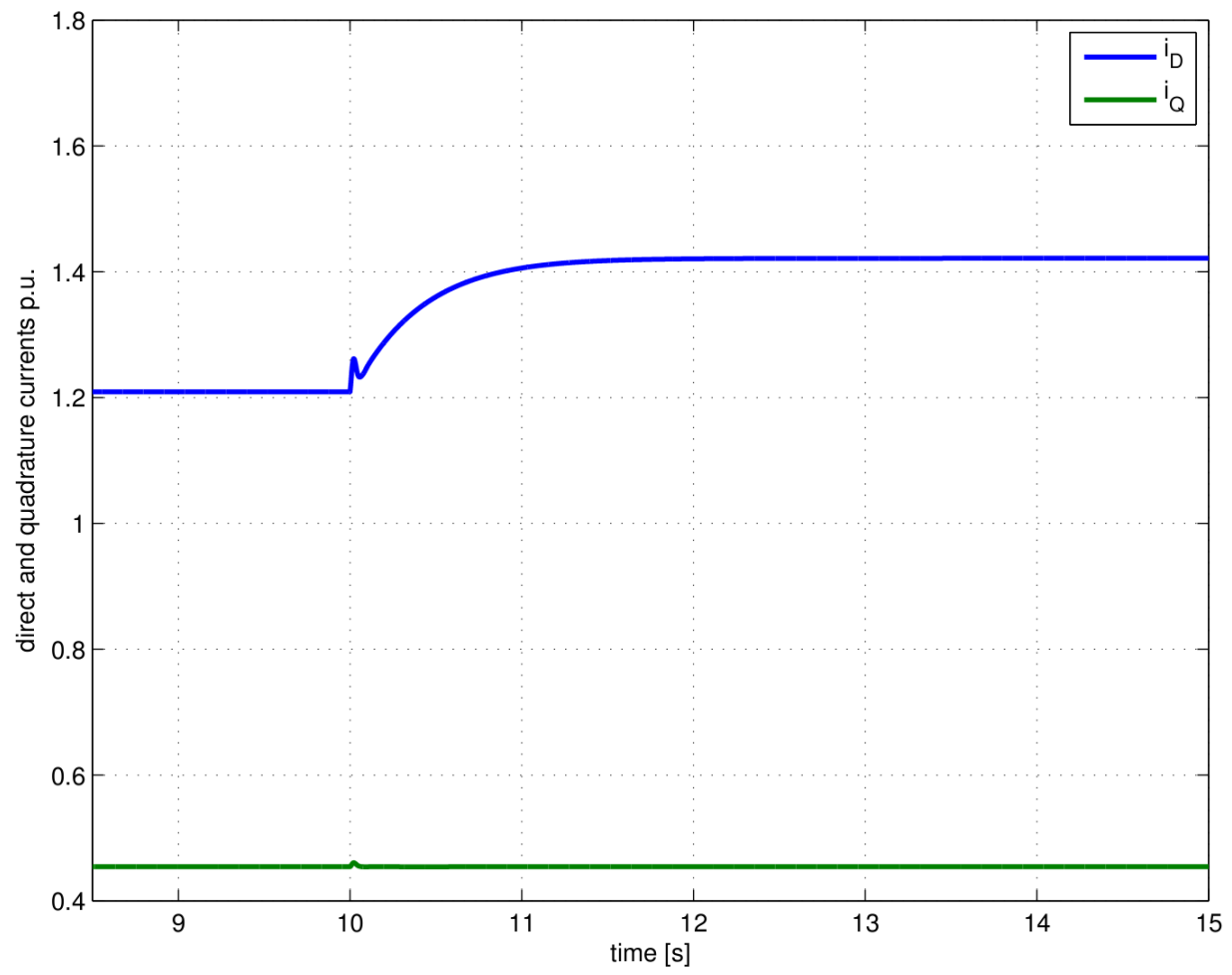


Figure 14. DC Link voltage transient due to the grid under-voltage.

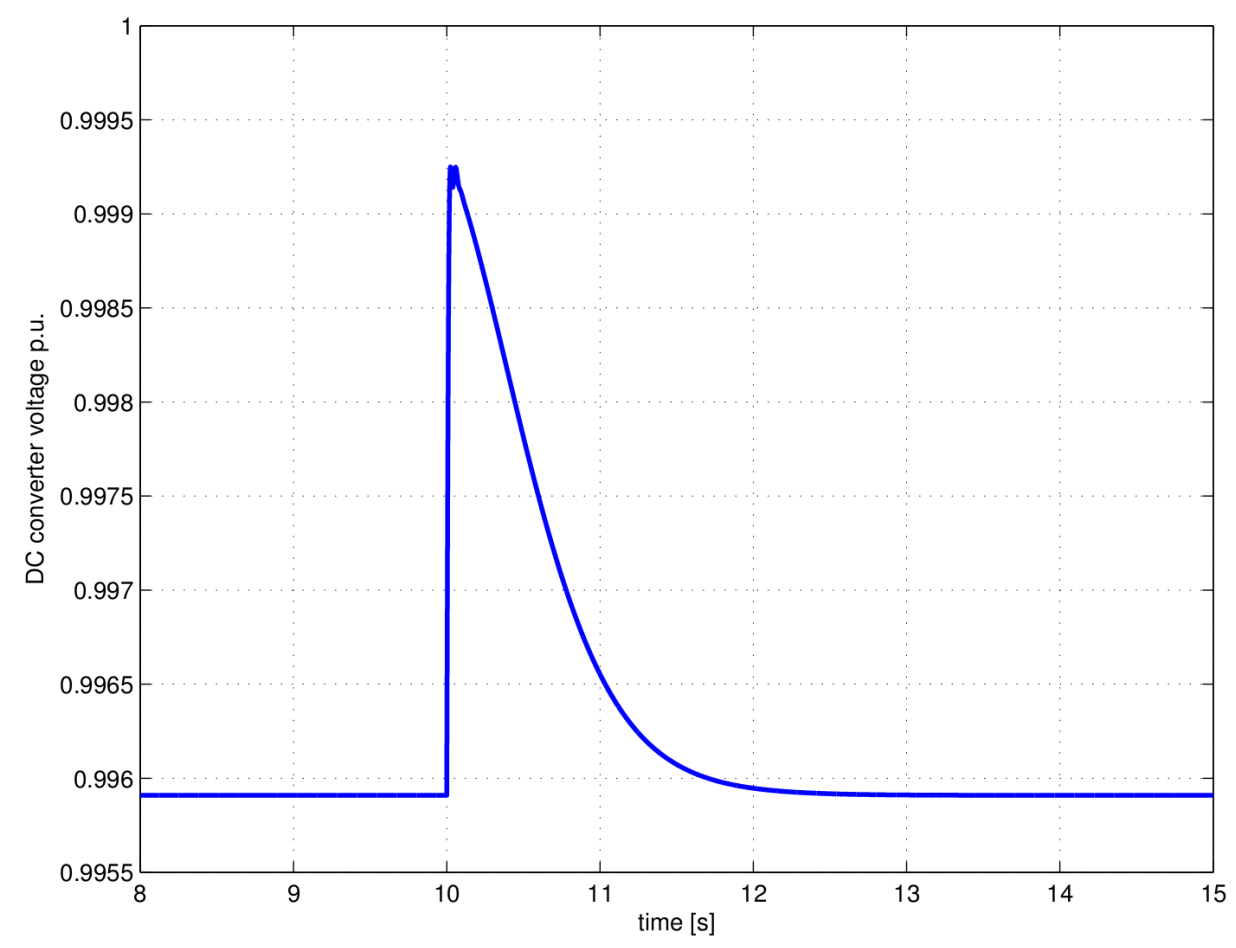

\section{Conclusions}

This paper has presented a comprehensive analysis of a power generation system from PV source. Its power flow control system is characterized by a reduced power equipment, i.e., by the presence of a simple three-phase inverter connected to a power AC grid with no intermediate DC-DC converter. The absence of the DC-DC converter makes the system more reliable, affordable, cheaper and efficient with respect to a traditional one where the DC-DC converter is present. The comprehensive mathematical analysis exposed in the paper has shown that the three-phase inverter used in the system presents two degrees of freedom. These ones are utilized for the simultaneous MPPT and AC-side power flow control through a stable synchronization to the power grid.

The accomplished analysis has shown also the way to determine the duty cycle of the inverter to deliver active and reactive power within certain limits, avoiding a degradation of the performances. By decoupling direct and quadrature control channels for AC currents, active and reactive power may be managed and controlled independently. Simulation results, obtained with the average model in the rotating coordinates frame, have validated the control system, showing the validity of the chosen strategy that needs a minimal knowledge of system parameters.

\section{Acknowledgments}

This work has been sustained by the SDESLAB (Sustainable Development and Energy Savings Laboratory) within the University of Palermo and by MIUR on PRIN 2008 funds. 


\section{References}

1. Ramakumar, R.; Bigger, J. Photovoltaic systems. Proc. IEEE 1993, 81, 365-377.

2. Ramakumar, R.; Butler, N.; Rodriguez, A.; Venkata, S. Economic aspects of advanced energy technologies. Proc. IEEE 1993, 81, 318-332.

3. Corzine, K.; Wielebski, M.; Peng, F.; Wang, J. Control of Cascaded Multi-Level Inverters. In Proceedings of IEEE International Electric Machines and Drives Conference, Madison, WI, USA, 1-4 June 2003; pp. 1549-1555.

4. Jian, L.; Xianggen, Y.; Zhe, Z. A New Three-Level NPC Inverter Based on Phase Individual DC-Link Circuit and High Quality Digital SPWM Control Technology. In Proceedings of International Conference on Communications, Circuits and Systems (ICCCAS 2009), Malpitas, CA, USA, 23-25 July 2009; pp. 732-736.

5. Saridakis, S.; Koutroulis, E.; Blaabjerg, F. Optimal Design of NPC and Active-NPC Transformerless PV Inverters. In Proceedings of 3rd IEEE International Symposium on Power Electronics for Distributed Generation Systems (PEDG), Aalborg, Denmark, 25-28 June 2012; pp. 106-113.

6. Teodorescu, R.; Liserre, M.; Rodriguez, A. Grid Converters for Photovoltaic and Wind Power Systems; IEEE, John Wiley and Sons: Hoboken, NJ, USA, 2011.

7. Victor, M.; Greizer, F.; Bremicker, S.; Hubler, U. Method of converting a direct current voltage from a source of direct current voltage, more specifically from a photovoltaic source of direct current voltage, into a alternating current voltage. U.S. Patent 2005/0286281 A1, 29 December 2005.

8. Shmid, H.; Siedle, C.; Ketterer, J. DC/AC converter to convert direct electric voltage into alternating voltage or into alternating current. U.S. Patent 7046534, 16 May 2006.

9. Hantshell, J. German Patent Application, Pubblication Number DE102006010694 A11, 20 September 2007.

10. Genduso, F.; Miceli, R. Power Quality Savings with Controlled Fault-Tolerant Power Converters. In Proceedings of International Conference on Theory and Application of Modeling and Simulation in Electrical Power Engineering, Paris, France, 6-8 June 2011; pp. 1-6.

11. Di Tommaso, A.; Genduso, F.; Miceli, R. A General Mathematical Model for Non-Redundant Fault-Tolerant Inverters. In Proceedings of International Electric Machines \& Drives Conference (IEMDC), Niagara Falls, Canada, 15-18 May 2011; pp. 405-710.

12. Di Tommaso, A.; Genduso, F.; Miceli, R. A Geometrical Simple Approach for Power Silicon Devices Fault Detection and Fault-Tolerant Operation of a Voltage Source Inverter. In Proceedings of International Conference on Electrical Machines (ICEM'2012), Marseille, France, 2-5 September 2012; pp. 1524-1530.

13. Genduso, F.; Miceli, R. A General Mathematical Model for Non-Redundant Fault-Tolerant Inverters. In Proceedings of IEEE InternationalElectric Machines \& Drives Conference (IEMDC), Niagara Falls, Canada, 15-18 May 2011; pp. 705-710. 
14. Cecati, C.; Genduso, F.; Miceli, R.; Ricco Galluzzo, G. A Suitable Control Technique for FaultTolerant Converters in Distributed Generation. In Proceedings of IEEE International Symposium on Industrial Electronics, Gdansk, Poland, 27-30 June 2011; pp. 107-112.

15. Genduso, F.; Di Tommaso, A.; Miceli, R.; Ricco Galluzzo, G. Development of Diagnostic Systems for the Fault-Tolerant Operation of Micro-Grids. In Proceedings of International Symposium on Power Electronics Electrical Drives Automation and Motion, Pisa, Italy, 14-16 June 2010; pp. $1645-1650$.

16. Di Tommaso, A.; Genduso, F.; Miceli, R.; Ricco Galluzzo, G. Experimental Validation of a General Model for Three Phase Inverters Operating in Healthy and Faulty Modes. In Proceedings of International Symposium on Power Electronics, Electrical Drives, Automation and Motion, Sorrento, Italy, 20-22 June 2012; pp. 50-55.

17. Kerekes, T.; Teodorescu, R.; Rodriguez, A.; Vasquez, G.; Aldabas, E. A new high-efficiency single-phase transformerless PV inverter topology. IEEE Trans. Ind. Electron. 2011, 58, 184-191.

18. Chen, Y.; Smedley, M. A cost effective single stage inverter with maximum power point tracking. IEEE Trans. Ind. Electron. 2004, 19, 365-377.

19. Alakula, M. Power Electronics; University of Lund, Internal Pubblication for the Power Electronics Undergraduated Courses: Lund, Sweden, 1991.

20. Mohan, N.; Undeland, T.; Robbins, W. Power Electronics, Converters, Applications and Design; John Wiley and Sons: Hoboken, NJ, USA, 2003.

21. Joos, G.; Salazar, L. PSPICE simulation of three-phase inverters by means of switching functions. IEEE Trans. Ind. Electron. 1994, 9, 35-42.

22. Mohamed, A.; El-Sayed, O.; Al-Naseem, A. Efficient Utilization of Photovoltaic Energy for Supplying of Remote Electric Loads. In Proceedings of 46th International Universities Power Engineering Conference (UPEC 2011), Brighton, UK, 5-8 September 2011; pp. 1-5.

23. Di Tommaso, A.; Genduso, F.; Miceli, R. Comprehensive Analytical Investigation for PV Plants and Their Control System with Reduced Power Electronics Equipments. In Proceedings of Electrical Vehicles and renewable Energies Conference (EVER 2012), Montecarlo, Monaco, 22-25 March 2012; pp. 1-5.

24. Hussain, K.; Muta, I.; Hoshino, T.; Osakada, M. Maximum Photovoltaic Power Tracking: An Algorithm for Rapidly Changing Atmospheric Conditions. IEE Proc. Gener. Transm. Distrib. 2005, 142, 953-959.

25. Ghartemani, M.; Khajehoddin, S.; Jain, P.; Bakhshai, A. Problems of startup and phase jumps in PLL systems. IEEE Trans. Power Electron. 2012, 27, 1830-1838.

26. Di Tommaso, A.; Miceli, R. A New High Accuracy Software Based Resolver-to-Digital Converter. In Proceedings of the 29th Annual Conference of the IEEE Industrial Electronics Society (IECON'03), Roanoke, VA, USA, 2-6 November 2003; pp. 2435-2440.

27. Sen, B.; Sharma, D.; Babu, B. DSRF and SOGI Based PLL-Two Viable Scheme for Grid Synchronization of DG Systems during Grid Abnormalities. In Proceedings of 2012 Students Conference on Engineering and Systems (SCES), Ullahab, India, 16-18 March 2012; pp. 1-6. 
28. Rodriguez, A.; Luna, A.; Munoz-Aguilar, R.; Etxeberria-Otadui, I.; Teodorescu, R.; Blaabjerg, F. A stationary reference frame grid synchronization system for three-phase grid-connected power converters under adverse grid conditions. IEEE Trans. Power Electron. 2012, 27, 99-112.

(C) 2012 by the authors; licensee MDPI, Basel, Switzerland. This article is an open access article distributed under the terms and conditions of the Creative Commons Attribution license (http://creativecommons.org/licenses/by/3.0/). 